\title{
VERSATILITY OF HERBS
}

\author{
Nivedita. K, Swati Shourie, Shwetha Sukumaran* \\ P.U. Antony** Prathiba Vinay***
}

"The earth was not given to us by our parents, it was loaned to us by our children."

\section{Aim}

- Kenyan proverb

To create an awareness among people, promoting medicinal plants for health care, conservation and sustainable utilization of plants.

\section{In the Beginning}

Herbs have been with us from the beginning of time. Man has used herbs to treat his illnesses for thousands of years. Most of the world's people still continue to use herbs to the benefit of their bodies. The reason being that they're safe and extremely reliable, with no side effects. They put the body in fune with nature as God intended. The bible tells us many times to use herbs for the benefits of the body's health. In Genesis, God tells us, "I have given you every herb bearing seed, which is upon the face of the earth, and every tree, in which is the fruit of a tree yielding seed; to you it shall be for meat." In Ezekiel, the Lord says, "The fruit of the tree is for man's meat, and the leaves for man's medicine.

* Final Year BSC. CBZ Studuents, Christ College, Bangalore.

** SGL, Department of Zoology, Christ College, Bangalore

*** Founder President of TULSI, Bangalore 


\section{Egyptians}

Ancient Egyptians were highly skilled with herbs. The Papyus Ebers, an ancient text written in $1500 \mathrm{BC}$, contains references to more than 700 herbal remedies, including herbs such as aloe, caraway seeds, poppy, and garlic.

\section{Chinese}

The Chinese have practiced herbal use for 5000 years. There is one Chinese medical text written in $2700 \mathrm{BC}$ in which thirteen herbal prescriptions were listed. The Chinese are noted for their knowledge and use of ginseng. Many Chinese believe regular use of this herb prolongs life.

\section{Greeks}

Hypocrites, "the father of medical literature" as he is called, was so far as we know the first man to practice medicine as an art. Hypocrites believed and taught that in nature there was strength to cure disease. Often, Hypocrites used diet and herbs as the basis of treatment.

\section{Romans}

The medical inheritance of ancient Egypt passed to Greece, then to Rome. The Roman Empire used herbal remedies quite extensively. Mandrake herb was used in Roman times as an anesthetic.

\section{Present Day}

Herbalists today believe and seek to help people build their good health with natural sources. Herbs are considered to be food rather than medicine because they're complete, all natural and pure, as nature intended. When herbs are taken, the body starts to be cleansed, purifying itself. This slowly gives the body nutrients to function as God intended. Unlike chemically synthesized, highly concentrated drugs that produce countless side effects, herbs can realign the body's defenses, helping it to heal itself without any side effects. Herbs do not produce instant miracle cures, but rather offer a way to put the body in tune with nature. 


\section{Definition, Number, and Types of Herbs Available}

Early herb gardens were the major source for food seasoning. The need for homegrown herbs, however, declined with the advent of modern stores. Today, many gardeners are rediscovering the joy and pleasure of producing their own herbs.

\section{Definition of Herb}

From the botanical viewpoint, an herb is a seed plant that does not produce a woody stem like a tree. But an herb will live long enough to develop flowers and seeds.

\section{Number of Herbs Available}

A true herb connoisseur can select from a wide variety of common and not-socommon herbs. For example, the E \& A Evetts Ashfields Herb Nursery of Shropshire, England, lists 57 herbs, 16 mints, 17 onion-type herbs, 20 sages, and 17 thymes in a recent catalog.

The Brooklyn Botanic Garden Handbook on Herbs lists 73 different types of herbs.

Some herbs fit into one or more classifications according to use - culinary, aromatic, ornamental, and medicinal.

\section{Culinary Herbs}

Culinary herbs are probably the most useful to herb gardeners, having a wide range of uses in cooking. These herbs, because of their strong flavors, are generally used in small quantities to add flavor. Parsley, produced in the largest amount, is used mostly as a garnish. Next in popularity is sage - an important flavoring in pork sausage. Other popular culinary herbs include chives, thyme, savory, marioram, mint, and basil.

\section{Aromatic Herbs}

Aromatic herbs have some novel uses and are not as popular to grow. Most have pleasant smelling flowers or foliage. Oils from aromatic herbs can be used to produce perfumes, toilet water, and various scents. For home use, the plant parts are used intact, offen to scent linens or clothing. When dried, many aromatic herbs 
will retain their aroma for a considerable period. Some common aromatic herbs include mint, marjoram, lovage, rosemary, and basil.

\section{Ornamental Herbs}

Ornamental herbs have brightly colored flowers and foliage. Many have whitish or light-colored flowers. Valerian has crimson blossoms while borage and chicory are blue-flowered. Such herbs as variegated thyme, mint, lavender, and chives produce variegated foliage.

\section{Medicinal Herbs}

Medicinal herbs have long been thought to have curative powers. But while present medical knowledge recognizes some herbs as having healing properties, others are highly overrated. Medicinal herbs should be used carefully. Some herbs are harmless while others can be dangerous if consumed.

\section{Herb Types}

Herbs also can be classified as annuals, biennials, and perennials. Annuals bloom one season and then die. Biennials live for two seasons, blooming the second season only. Once established, perennials over winter and bloom each season.

\section{Aloe Vera}

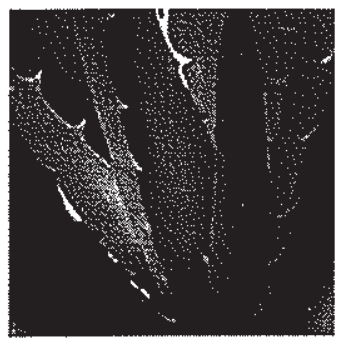

Family: Liliaceae

Botanical Name: Aloe vera(L.)Burm.f

Sanskrit Name: Kumari

Kannada Name: Loole sara

Origin: Unknown

Distribution: Mediterraneán canary islands. Naturalised in Florida, West Indies, Central America and Asia

Description: It is a perennial herb with fleshy ensiform leaves, flower are reddish yellow in long scapes. Leaves are smooth, shiny with irregular white patches; they are pale green in colour. Fruit is a capsule, oval shaped and long. 
How to Propagate: Mother plant produces suckers. Each mother plant may produce upto 6 suckers. These are separated along with the leaves and roots. They are planted in the soil medium containing manure, loam, broken bricks and coarse sand. This is done in the month of October to December.

Parts Used: Leaves

\section{Uses:}

- Liver and sleen ailments

- Eye troubles

- Chronic constipation

- Aloe species are used in a host of diseases, particularly of the digestive system

- minor burns

- stretch marks

- for cleansing and dressing of wounds

- dandruff

Chemical Composition: Plant contains aloesone and aloesin. Mucilage contains sugars. Leaves contain barbuloin, glycoside and isobarbuloin and B-barbuloin, free anthraquinone like loe emodin, iso-emodin, free and cinnamoylate-8-methyl7-hydroxyoloins.

\section{Tinospora Cordifolia}

Family: Menispermaceace

Botanical Name: Tinospora cordifolia (Willd) Hook.f and Thomson

Common Name: Amrutha balli

Origin: Unknown

Distribution: India, Bangladesh, Sri Lanka

Description: It is a large climbing shrub; bark is greyish brown or creamy white, warty; leaves are membranous, broady ovate, cordate at base; flower are greenish 
yellow, appearing when the plant is leafless in axillary and terminal racemose or panicles.

Parts Used: Stem, root and fruit

Uses:

- It is an antigonorrhoeic

- it is used in skin disease

- it is an antiinflammatory

- it is antidiabetic

- starch from root and stem is used as antidiarrhoeal, fruittonis, antirheumatic

- stem and fruit are used in jaundice

- stem is used as antiviral and anti cancer

Chemical Composition: Plant contains quartenary alkaloids magnoflourine tembestarine. Stem contains furanoid diterpene-tinosporin tinosporide, tinosporidine, B-sitosterol. Stemwood contains tinosporaside. Leaves contains cordifol, heptacosanol and octacosanol.

\section{Bacopa Monnieri}

Family: Apiaceae

Botanical Name: Bacopa monnieri(L.) Pennel

Common Name: Brahmi

Origin: Unknown

Distribution: Paleotropical

Parts Used: Leaves

Uses:

- Improve infelligence

- used in epilepsy 
- insanity

- other nervous diseases

Chemical Composition: Plant contains nicotine, luteolin, luteolin-7-glucoside bacogenin A1, A2, A3, betulinic acid, D-mannitol and a glycoside, saponinsbacoside $A, A 3$ and bacoside $B$ and monnierin, stigmasterol, B-sitosterol, dammarane type triterpenoid saponins-Bacosaponins $A, B$ and $C$

\section{Centella Asiatica}

Family: Apiaceae

Botanical Name: Centella asiatica (L.) Urban

Common Name: Saraswathi yele

Origin: Unknown

Distribution: paleotropical

Description: It is a trailing herb, rooting at nodes, leaves are reniform, crenate: flower are brownish, subsessile in umbels; fruits laterally compressed.

Parts Used: Leaves

Uses:

- It is diuretic and tonic

- If is also used in leprosy

- Enhances intelligence, memory power, and body immunity

Chemical Composition: If contains triterpenoid asiaticoside-A and asiaticosideB, triterpene acid, madasiatic, two triterpene acids - brahmic acid, isobrahmic acid and two saponins - brahmoside and brahminoside, a triterpene glycosidethankuniside acid, thankunic acid: fresh leaves contain essential oil, fatty oils, sitosterol, tannin and resinous substance: leaves and roots contain resin, bitter principle vellarine, pectic acid: Dried plants contain alkaloids hydocotylin, glycoside asiatcoside. 


\section{Rosa Sinensis}

Family: Malvaceae

Botanical Name: Rosa sinensis. Linn

Common Name: Hibiscus, gurhal

Origin: East Africa

Distribution: Naturalised in India almost everywhere

Description: It is an evergreen woody gaacious plant, flowers are red and also available in many other colours.

Parts Used: leaves, flower and roots.

Uses:

- Decoction of flower is used in bronchial catarrh

- for hair problems

- cough

- veneral disease

- gonorrhea

Chemical Composition: leaves - alkaloid, glycosides, fatty material, resin, sterols; flowers - quertetin, quercetin, cyanidinchloride

\section{Coelus Amboinicus}

Botanical Name: Coelus amboinicus Lour

Common Name: Dhoddapatre, Karpuravalli

Origin: Unknown

Distribution: Wildely cultivated in Indo Malesian region, introduced in Mexico and U.S.A.

Parts Used: Leaves 
Uses:

- indigestion

- diarrhoea

- mild wheezing

- cough

- leaves applied as poultice in centipede or scorpion sting

Chemical Composition: Leaves exalacetic acid, cirsimaritin, and B-sitosterol

\section{Some Other Herbs...}

Wedelia Chinensis

Family: Asteraceae

Botanical Name: Wedelia chinensis

Sanskrit Name: Peetabhrngaraja

Kannada Name: Garuga

Origin: Indo Malayan origin

Distribution: India, Sri Lanka, China, Japan

Parts Used: leaves and flower

Uses: nafural dye, conditioner.

\section{Cinchona Officinalis}

Family : Rubiaceae

Botanical Name : Cinchona Officinalis

Common Name: Quinine, Peruvian Bark, Quinine Bark

Parts Used: Quinine isolated from bark 
Habitat: Cultivated in Nilgiri Hills

Uses: Quinine is Bitter, Astringent, Acrid, Thermogenic, Febrifugre, Oxytoxic and Anodyne. It is digestive, antipyrefic, cardiotonic, dystocia, eumbago etc.

\section{Henna}

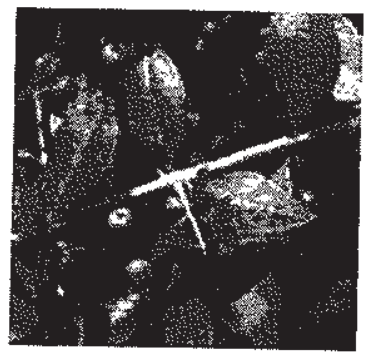

Family : Lythraceae

Botanical Name : Lawsonia Inermis

Common Name: Henna, Al-khanna, Al-henna, Jamaica Mignonette, Mehndi, Mendee, Egyptian Privet, Smooth Lawsonia

Parts Used: Flowers, Powdered Leaves, Fruits

Habitat : Scarcely in dry decidious forests, widely cultivated as a hedge plant.

Uses : The roots are bitter, refrigerant, depurative, diuretic, emmenagouge; abortifacient and trichogenous and is useful in burning sensation, leprosy skin diseases and amenorrhoea. It is used in pre mature graying of hair. Henna is widely used for drawing tatoos, arts and designs. Leaves are useful in wounds, ulcers, strangury cough, bronchitis, dysentery etc.

\section{Punica Granatum}

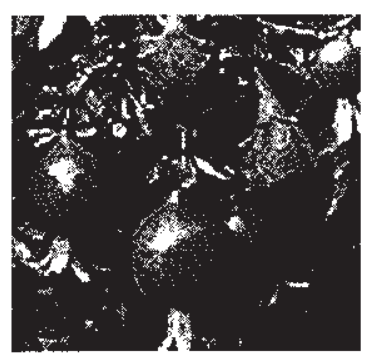

Family: Puniacaceae

Botanical Name : Punica Granatum

Common Name: Pomegranate, Anar

Parts Used: Seeds, Flowers

Habitat : Commonly cultivated as ornamental and fruit tree.

Uses : A decoction of seed is used to treat syphilis. Juice used to treat jaundice and Diarrhoea. Juice of flower is used to treat nose bleeds. The fruit pulp and the seed are stomachic. 


\section{Terminalia Arjuna}

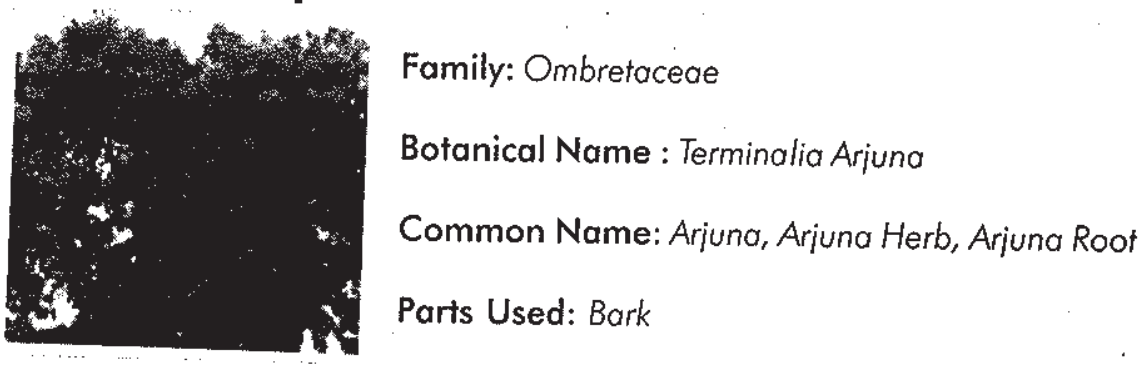

Uses : The bark is astringent, sweet, acrid, cooling, aphrodisiac, cardiotonic, urinary astringent, expectorant, alexiteric and is useful in fractures, ulcers, cirrhosis of the lever, hyperhidsis, otalgia and hypertension.

\section{Zingiber Officinalis}

Family: Zingiberaceae

Botanical Name: Zingiber Officinalis

Common Name: Calamus, Sweet Ginger, Ginger Root, Sonth (Dried)

Parts Used: Fresh and dried fruif

Habitat: South East Asia and throughout India.

Uses: Clinically proved as prophylactic of Nausea and vomiting associated with motion, sickness, sea sickness and pregnancy. Known for its gastrointestinal benefits and as an anti inflammatory and carminative.

\section{Neem Neem Neem \& Neem}

Azadirachta Indica

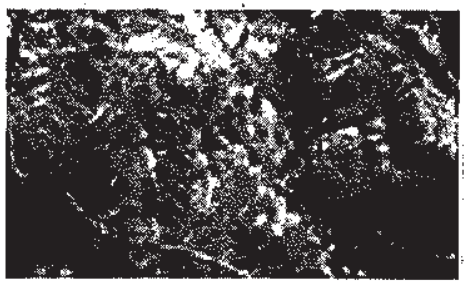

Family Name: Meliaceae

Botanical Name : Azadirachta indica

Common Name: Lilac, Margosa Tree, Neem, Neem Chal

Parts Used: Leaves, Flower, Oil, Seed

Habitat: It is evergreen and grows throughout India. 
Uses: Vermifuge, Insecticide, Astringent, Tonic and Antispetic. If possesses anti diabetic, anti bacterial and anti viral properties and used successfully in cases of stomach, worms and ulcers. Root bark possesses anstringent, tonic and antiperiodic properties. It is also useful in Malarial fever. The oil is used in making Neem based soaps, shampoos and toothpaste.

\section{Way back when...}

Shortly after Julius Caesar established the Roman Empire, Pliny the Elder issued a public complaint: the ever-increasing volume of medicines imported from India was causing a serious drain on the Roman gold treasury.

By that time, medical practitioners on the Indian subcontinent had been studying and documenting the effects of hundreds of botanical compounds for more than 2,500 years. As early explorers traveled to India to trade for gold, silks and spices, carefully compiled Indian medicines were also brought back to Persia, Mesopotamia, Egypt, Greece and Rome.

The first indication that neem was being used as a medical treatment was about 4,500 years ago. This was the high point of the Indian Harappa culture, one of the great civilizations of the ancient world. Excavations at Harappa and MohenjoDaro in north-western and western India that date to that period found several therapeutic compounds, including neem leaves, gathered in the ruins.

Although the ancient methods for developing new drugs were crude, in some ways they were remarkably similar to the complex scientific techniques used today. Rather than laboratory studies, however, Indian Vedic medical practitioners moved directly to clinical trials. They tested different drugs on different patients to learn and document successful treatments and potential side effects. Of course, these tests took dozens of scientists hundreds of years to complete. They had the luxury of time with no pharmaceutical companies rushing to get new products to market or attorneys to file malpractice suits.

Among the most ancient surviving documents that have been translated are the Caraka-Samhita (approximately 500 B.C.) and Susruta Samhita (approximately 300 A.D.). These books are the foundation of the Indian system of natural healing, Ayurveda. In these ancient texts neem is mentioned in almost 100 entries for treating a wide range of diseases and symptoms, most of which continue to vex humanity. Long revered for its many healing properties, neem came close to providing a cradle-to-grave health care program and was a part of almost every aspect of life in many parts of the Indian subcontinent up to and including the modern era. 
The Sarira Sthanam recommended that newborn infants should be anointed with herbs and oil, laid on a silken sheet and fanned with a branch of a neem tree with ample leaves. As the child grew it was given small doses of neem oil when ill and bathed with neem tea to treats cuts, rashes and the lesions of Chicken pox. Daily brushing with neem twigs helped kept both child and adult free of cavities and diseases of the gums. At the wedding ceremony neem leaves were strewn on the floor of the temple and the air fanned with neem branches. During adulthood neem bark was burned to make the red ash to be used for religious decoration of the body and neem branches were fanned at the front of religious processions. Neem oil lit the night in small lamps. The wood was used to cook the daily meals of beans and grains that had been kept free of insects during storage by mixing them with a light coating of neem oil or by mixing them with neem leaves. Ayurvedic preparafions with neem were given for illnesses and neem wood used to make the roof of the house. And at the time of death, neem branches cover the body and neem wood was burned in the funeral pyre.

Neem was so much a part of Indian life that most people were not even conscious of how many ways neem impacted their lives. It has really only been since the dramatic interest in neem by the people of Europe and the United States that they have come to realize the value and significance of neem. A movement to protect the relatively few neem trees in India and the many products given by them is growing as the people of India see the possibility that richer Western nations will create a larger demand for and increase the price of neem products.

To address this potential problem, the Indian government is considering legislation that would ban the export of neem seeds - now regarded as a national treasure — and limit foreign sales to neem oil and manufactured products only.

The neem tree (Azadirachta indica) is a tropical evergreen related to mahogany. Native to east India and Burma, it grows in much of southeast Asia and west Africa. A few trees have recently been planted in the Caribbean and several Central American countries. Outdoors, in locations where temperatures don't drop much below freezing, it may reach up to 50 feet tall. Neem trees are very fast growers. They may grow to as much as 20 feet in height in just three years from seed planting. It will grow where rainfall is as little as 18 inches per year and thrives in areas that experience extreme heat of up to 120 degrees $F$. They are reported to live for up to 200 years.

Its blooms are small, white flowers with a very sweet, jasmine-like scent. Its edible fruit - loved by children in Africa - is about $3 / 4$ of an inch long. A neem tree generally begins bearing fruit at three to five years old, and can produce up to 110 lbs. of fruit annually when mature. 
Neem makes an ideal indoor plant because it grows well with a minimum of maintenance. For optimum growth, neem should be placed near a sunny window during the winter and moved outside during summer months. However, they will survive indoors even if they don't receive any natural light at all.

Neem and the Immune System: Neem, especially neem bark, is recognized for its immunomodulatory polysaccharide compounds. These compounds appear to increase antibody production. Other compounds in neem enhance the immune system via a different mechanism; the cell- mediated immune response, the body's first form of defense. Only when this system appears to be unable to stop an infectious onslaught is the more massive immune system involved.

Neem oil acts as a non-specific immuno-stimulant that activates the cell mediated immune response. This then creates an enhanced response to any future challenges by disease organisms. When neem oil was injected under the skin there was a significant increase in leukocytic cells and perioneal macrophages showed enhanced phagocytic activity and expression of MHC class Il antigens. Production of gamma interferon was also induced by the injection. Spleen cells showed higher lymphocyte reaction to infection but did not augment anti-TT antibody response.

Water soluble neem leaf extracts, when taken orally, produced an increase in lymphomatic counts and both red and white blood cells as well as lymphocyte counts. In studies on the birth control effects of neem the major factor in that effect appears to be an increase in the immune response where neem has been applied that causes the body to reject the foetus a foreign body.

By enhancing the cellular immune response most pathogens can be eliminated before they cause the ill feeling associated with disease. This mechanism could also help in diseases that involve the immune system, like AIDS. Ingesting small quantities of neem leaf or bark powder every other day or drinking a mild neem tea will enhance antibody production and the body's cell-mediated immune response, helping to prevent infections.

\section{Other Products}

Neemaura is environment friendly natural Neem bitterns, non toxic and safe biodegradable urea coating agent containing Neem Triterpenes inhibit the growth of nitrifying bacteria resulting in delayed transformation of ammoniacal nitrogen into nitrite nitrogen. This ensures slow and continuous availability of nitrogen matching the requirements of crop plants during their life cycle and effectively retards the nitrification of urea. Neemaura coated urea mineralizes much slower 
than plain urea at least two to three times under soil conditions by controlling the multiplication process of soil borne bacteria like, Nitrosomanas and Nitrobacter which are responsible for nitrification. Neemaura formulation contains neem bitters and sulphurous compounds, which are mainly responsible for retarding the process of bacterial action and protects urea from leaching, volatilization and also protects crop from insect pest result in higher yields.

\section{Biogrow}

Bio-organic soil enricher made from complete biodegradble organic Neem cake which is manure for green earth. Neem cake is rich in sulphur compounds, in addition to its intrinsic N.P.K. value, it possess bitter terpenoids such as EpinimbinA natural nitrification inhibitor. It is a rich source of plant nutrients, growth promoting substances, nitrogen fixers and phosphorous solubilisers which contribute to vigorous growth and high quality yield.

\section{Neemgard}

The extracted powder from processed neem leaf, which is used in several herbal cosmetic preparations, medicated herbal tea, health, and hygiene products. Neemgard effectively controls various fungus and pests during storage of seeds. This is also used at nursery level for sowing of seeds and it controls seeds from attack of various fungus and viruses particularly nematodes.

\section{NeemHit Petspray}

NeemHit Petspray is a formulation containing neem kernel extract containing azadirachtin for prevention parasite attacks by scabies, eczema, and mange organisms in pets. The protective thin layer Azadirachtin coating is firmly attached to the animal's skin and fur and protect it in a totally natural way, from fleas, lice, ticks, mosquito, sandfly, species of midge etc and which also act as an antifeedant, deterring and repelling all young fleas and killing flea eggs or larvae. NeemHit petspray totally natural product for the skin, $100 \%$ ecologically safe, environmentally friendly with antibecterial, antifungal, antiviral properties, that has value-added benefits, like an active that arrests any inflammation caused by a prior bite, as well as help to improve the condition of the skin and hair.

\section{Chemistry of Ingredients of Neem}

Neem plants, as do all other plants, contain several thousands of chemical constituents. Of special interest are the terpenoids are known from different parts of 
the neem plant. Of its biological constituents the most active and well studied compound is Azadirachtin. However, in most traditional preparations of neem as pesticide or medicine a mixture of neem chemicals are present and provide the active principles. Several different kinds of azadirachtins ( $A$ to $K$ ) have been isolated, the most abundant of which is Azadirachtin - A. The neem terpenoids are present in all parts of the plant, in the living tissues. Recently, the site. of synthesis and accumulation of the neem chemicals has been identified as secretory cells. Secretory cells are most abundant in the seed kernels. The secretory cells can be seen with iodine solution. Besides the terpenoids, neem also contains more than 20 sulphurous compounds responsible for the characteristic smell of crushed seeds and neem oil.

\section{Toxicity}

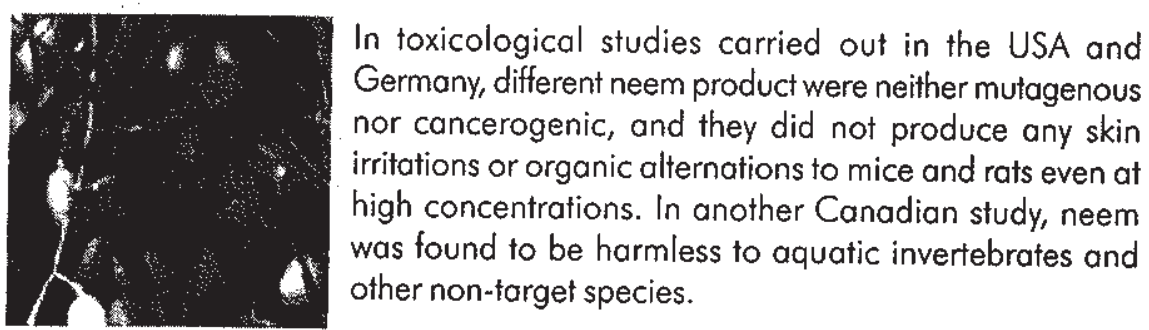

\section{Patency-Boon or Curse?}

Haldi (turmeric) is not only the most important spice in curry, it also known since hundreds of years to have many medical uses. Haldi has been used as a wound healing agent can be found in 200-year-old Ayurvedic scripture. These traditional knowledge systems are communicated by word of mouth. Now the western scientists have 'discovered' our traditional bio-resource as a part of profit, as they intend to trade. The faces of brides are painted with Turmeric as a decorative to make them more glowing.

A long and storied history for this ginger-looking, brown-on-the-outside, brightorange-on-the-inside rhizome. It was listed as a coloring agent in an Assyrian herbal dating back to $600 \mathrm{BCE}$. It was used in sacrificial and religious rites in ancient india and China-and is used likewise to this day. In 1280, Marco Polo mentioned in his journals that he saw fumeric growing in the Fukien region of China, "... a vegetable that has all the properties of true saffron, as well the smell as the color, and yet it is not really saffron." Throughout medieval times, it was known in Europe as "Indian saffron" because of its coloring power, which, incidentally, is terrific. It's the yellow that puts the yellow in ballpark mustard-not to mention in curry. 
Curcumin, in tumeric, is an anti-inflammatory component that is helpful for arthritis. It not only helps with rheumatoid arthritis but it improves morning stiffness, the ability to walk for long intervals and is beneficial in diminishing joint swelling.

Tumeric has antibacterial making it ideal for healing wounds. In cases of acne turmeric can be made into a poultice and applied to the affected area or taken internally.

As an anti-fungal, it can be used for Athlete's Foot by making a paste. When combined with ginger, it can be used for ringworm.

Liver protection is another of its marvelous qualities. Tumeric stimulates the flow of bile, lessening the possibility of gallstones. If one is exposed to environmental toxins (and who isn't), turmeric will help break down the harmful substances. Chemotherapy patients and those consuming alcohol benefit from this wonderful herb. It has also been used to clear up diarrhea/dysentery. People suffering from Hepatitis $C$ also rely on turmeric for its beneficial effects on the liver.

Anti-cancer activity, as shown in Rutgers University, research demonstrates it is the curcumin in turmeric that helps prevent tumor development in their animal studies. Similar studies advocate tumeric for limiting growth of already formed fumors and may have the potential to deter other cancers such as breast, skin, stomach and colon.

Turmeric has found to be antioxidant, antibacterial, anticoagulant, antifungal, anti-inflammatory and antiviral. While there are very few contraindications, too much of anything is not a good thing.

The use of haldi (turmeric) comprises

- Increase immune system

- Treating musculo-skeletal disease

- Wound healing

- Dye

- Detect and warn cyanide adulterated food products

- Liquid seasoning compositions

- Metal colour complexes

- Tinted pit and fissure sealant 
- Colouring process and composition for food and beverages

- Process for producing water and oil as a colouring agent

- Conservation food (fish, meat, cooked food);

- Improve intestinal haemorrhage, bowel function, stops irritating substances, reduces fatty compounds and perhaps stops cancer etc

Now about 12 patents have been registered in the USA Although turmeric has long been used in India as a traditional medicine for treatment of various sprains and inflammatory conditions (Indian Journal of Medical Research, 1982). A lack of regulations is allowing foreign scientists to claim exclusive ownership of traditional medicine that we have used for centuries.

\section{Stealing Species}

The development of effective cures and preventives against life threatening diseases has been predominant concern of medical researches and scientists. These have been always done in the name of public interest or for the sake of humanity. In the past a successful new drug would invariably bring in profits and recognition for those who were behind it, but their motivation was to serve the people and not personal enrichment. This has changed during recent times and the emphasis is now on profits.

It is now common to see that many of the new discoveries becoming the private properties of individuals and firms with the help of intellectual property laws that grant patents over them. This is not confined to new drugs and their manufacturing processes, but has extended to therapeutic methods and even disease-causing (pathogenic) organisms. These have brought about a large number of hitherto unknown and unimagined problems, stifled a lot of research, delayed critically important research, increased the prices of drugs and diagnostic kits. The end result is that thousands of people have been denied the opportunity to live a healthy life.

The bitter gourd is found in many Asian countries where it is used both as a vegetable and as a medicine. In Sri Lanka, it is used to treat skin ailments and diabetes. It has been used in China since ancient times to treat infections and tumours. They have been eating the ripe fruit with the seeds to treat these illnesses. The effectiveness of these ancient medicinal plants in treating virus diseases had been subjected to a lot of research by Chinese scientists. Among them has been Lee-Huang, who subsequently went to the USA and then started patenting the work she was involved in China. Lee-Huang herself had admitted in an interview to Bio- 
world Today (Age old folk remedies resurface as recombinant anti-HIV, anti-fumour therapeutics by Davil N. Leff 23.10.1996) that bitter melon had been widely eaten in China and had been used in China and South-East Asia for centuries as an anti-infection and anti-tumour agent. Therefore, these patents that cover the MAP30 protein are another example of biopiracy and the victims are China and the other Asian countries.

Western countries are plundering the Third World's genetic resources (Biodiversity Conservation: The Threat to Ecological Conservation from Commercial Interests, Vandana Shiva, (Third World Network) 1990):

Wild species of plants and animals (many of which come from the Third World) contributed $\$ 340$ million per year to the US between 1976 and 1980 . The total contribution of wild species to the US economy has been estimated at $\$ 66$ billion. more than the total international debt of Mexico and the Philippines combined.

A wild tomato variety taken from Peru in 1962 has contributed $\$ 8$ million a year to the US tomato-processing industry. None of these profits or benefits have been shared with Peru.

The periwinkle plant from Madagascar is the source of 60 alkaloids which can treat childhood leukemia and Hodgkin's Disease. Drugs derived from this plant bring the US $\$ 160$ million a year. And another plant, Rauwolfa Serpentina, from India is the base for drugs which sell for up to $\$ 260$ million a year in the US alone.

The value of the South's genetic material for the pharmaceutical industry ranges from an estimated $\$ 4.7$ billion now to $\$ 47$ billion by the year 2000 .

\section{India Robbed Again}

First it was the neem tree, then turmeric, now another Indian medicinal plant is the target of foreign patents. Ashwagandha (Withania somnifera) has been used for thousands of years in the Ayurvedic system as an aphrodisiac, diuretic and for restoring memory loss.

Officials at the Department of Science and Technology (DST) said "one thing which is very obvious is that Ashwagandha is catching the attention of scientists, and more and more patents are being filed and granted on it by different patent offices around the world. "Seven American and four Japanese companies have filed or have been granted patents on Ashwagandha (Source: Diverse Women for Diversity, Norfolk Genetic Information Network PTI 15 May, 2001). 
Ashvagandha Withaia Somnifera grows in drier region of India and is also cultivated. A small or middle-sized undersurb, up to $1.5 \mathrm{~m}$ high, stern and branches covered with minute star-shaped hairs.

\section{Drug and Properties}

The drug consists of the dried roots of the plant. The antibiotic and antibacterial activity of the roots as wells as leaves have recently been shown experimentally (Jain, 2001):

- Useful in consumption, sexual, general weakness and rheumatism;

- Divertic i. e. it promotes urination, acts as a narcotic and removes functional obstruction of body;

- The root powder is applied locally on ulcers and inflammations.

- South Africa's Floral Heritage Sold Off

South Africa's National Botanical Institute (NBI) has sold the rights to develop new strains from national flora to US based company, Ball Horticultural. The unnamed government official who blew the whistle on the deal, which was signed two years ago, said "this effectively hands over South Africa's floral heritage to a US company in exchange for a pittance in royalties".

\section{Bitter Gourd Karela}

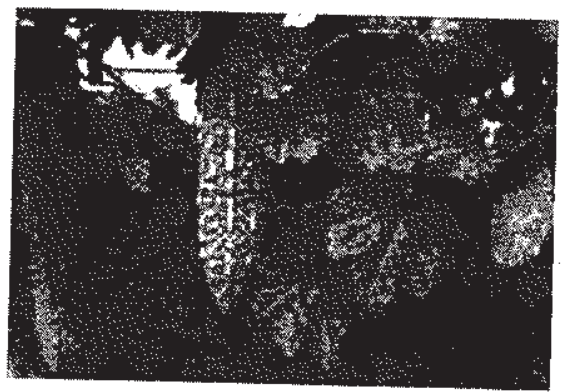

The bitter gourd is a common vegetable cultivated extensively all over Indian Subcontinent. It is 10 to $20 \mathrm{~cm}$. long, tapering at the ends and covered with blunt tubercles. The seeds are white in raw fruits and become red when they are ripe. There are two varieties of this vegetable. The large kind is long, oblong and pale green in color. The other kind is small, little oval and dark green. Both the types are bitter in taste. They turn reddish-orange when ripe. The original home of bitter gourd is not known except that it is a native of the tropics. It is widely grown in India, Indonesia, Sri Lanka, Malaysia, the Philippines, China and the Caribbean. 


\section{Natural Benefits and Curative Properties}

The bitter gourd has excellent medicinal virtues. It is antidotal, antipyretic tonic, appetizing, stomachic, antibilious and laxative. The bitter gourd is also used in native medicines of Asia and Africa.

Karela (bitter gourd) Subii - Vegetable Curry

\section{Diabetes}

The bitter gourd is specifically used as a folk medicine for diabetes. Recent researches by a team of British doctors have established that it contains a hypoglycaemic or insulin-like principle, designated as 'plant-insulin', which has been found highly beneficial in lowering the blood and urine sugar levels. It should, therefore, be included liberally in the diet of the diabetic. For better results, the diabetic should take the juice of about four or five fruits every morning on an empty stomach. The seeds of bitter gourd can be added to food in the powdered form. Diabetics can also use bitter gourd in the form of decoction by boiling the pieces in water or in the form of dry powder.

A majority of diabetics usually suffer from malnutrition as they are usually undernourished. Bitter gourd being rich in all the essential vitamins and minerals, especially vitamin $A, B 1, B 2, C$ and Iron, its regular use prevents many complications such as hypertension, eye complications, neuritis and defective metabolism of carbohydrates. It increases body's resistance against infection.

\section{Blood Disorders}

Bitter gourd is highly beneficial in the treatment of blood disorders like blood boils, scabies, itching, psoriasis, ring-worm and other fungal diseases. A cupful of fresh juice of bitter gourd mixed with a teaspoonful of lime juice should be taken, sip by sip, on empty stomach daily for four to six months in these conditions. Its regular use in endemic regions of leprosy acts as a preventive medicine.

\section{Respiratory Disorders}

Bitter gourd plant roots are used in folk medicine for respiratory disorders from ancient times. A teaspoonful of the root paste mixed with equal amount of honey or Tulsi leaf juice, given once every night for a month acts as an excellent medicine for asthma, bronchitis, Pharyngitis, colds and Rhinitis. 


\section{Alcoholism}

Leaf juice is beneficial in the treatment of alcoholism. It is an antidote for alcohol intoxication. It is also useful in liver damage due to alcoholism.

It is now karela, jamun \& brinjal: Biopiracy of rich Indian herbal wealth

Earlier R Basmati rice had been patented by Rice Tec Inc of USA. Now karela (bitter gourd), jamun (blackberry), gurmar, and brinjal have been patented by a MNC in the USA. The Supreme Court has issued notice to the Union Agriculture Ministry as the petitioner, Research Foundation for Science, Technology and Ecology (RFSTE), charged the Centre with failure to protect the country's biodiversity despite giving an assurance.

RFSTE counsel Sanjay Parikh said Attorney-General Soli Sorabjee had informed in 1998 about action taken by the government in protecting the biodiversity by bringing biodiversity legislation. As far as basmati rice was concerned, Sorabjee had said the government had already taken steps to challenge the grant of patent, but there has been no follow-up after that. Biopiracy is an epidemic. Earlier, neem, haldi, pepper, harad, bahera, amla, mustard, Basmati, ginger, castor, jaramla, amaltas, isabgol, and now karela and jamun have been patented under the USIPR system.

A patent number US6,900.240 was granted recently to Cromak Research Inc based in New Jersey, on edible herbal compositions for anti-diabetic properties. It comprised mixtures of at least two Indian herbs selected from a group consisting of 'syzygium jambolanum cumini', popularly known as jamun, 'momordica charantia' (bitter gourd or karela); 'solanum melongena' (brinjal or egg plant' and 'gymaema sylvestre' (gurmar) as anti-diabetes agents for their proposed use in reducing sugar.

Patents had been granted on May 4 last in the USA on edible herbal composition comprising mixtures of herbs selected from the group consisting of jamun, gurmar, karela and brinial useful as two hypolycemic agents. The investors include two non-resident Indians Onkar S. Tomar and Kirpanath Borah along with their American colleague Peter Glomski. The patenting of these anti-diabetic plants has again highlighted the problem of biopiracy of rich Indian herbal wealth.

A patent issued in the USA does not affect us dramatically, says the DirectorGeneral of the Council of Scientific and Industrial Research (CSIR), Dr R.A. Mashelkar. "It does not mean that one cannot use similar mixture in India for antidiabetic treatment. Yes, it may affect the possibility of our exporting such a mixture to the USA", says Mashelkar. India should be more active in filing the patents. 
"Since 1994 when the TRIPS came into force, the US in the last four years has granted upto 1,890 patents. Most of these have been from China. India's contribution has been meagre," says Mashelkar.

\section{Red Alert}

Decalepis hamiltonii wight and Arn.

Family: Periplocaceae

Sanskrit Name: Sariba, Sveta Sariva

Kannada Name: Magadi Beru

Threat Status: Endangered (AIC,D)- Globally

Habit: Woody Climber

Habitat: In open rocky slopes and cervices of dry to moist deciduous forests

Medicinal Uses: Tuberous roots are used as a cooling agent and blood purifier. Hence used to prepare refreshing drinks. Roots are used to cure indigestion, deficient digestive power, dysentry, cough, bronchitis leucorrhoea, uterine haemorrhage, skin disease, fever, thirst, vomiting, poisoning, rheumatism, anemia, debility, dysuria and blood diseases.

Trade Information: Local, regional, and national

\section{Garcinia indica (Thouars) Choisy}

Family: Clusiaceae

Sanskrit Name: Amlavetasa, Tintidika, Vrksamla

Kannada Name: Murgina Huli Mara, Murgul

Threat Status: Vulnerable $(A 7 c, d)$ - globally

Habit: tree

Habitat: coastal to evergreen forests

Medicinal Uses: The seed butter is used as a remedy in scrofulous disease, dysentry, mucous diairhoee and externally applied for excoriations, chaps, fissures of lips 
and as a substitute for spermaceti. The ripe fruit is anthelmintic and cardiotonic. Root bark, fruit and seed oil are used to cure piles, spruem abdominal disorder, mouth diseases, cardiac diseases and worm infections

Trade Information: Local regional and national

\section{Gloriosa superba L.}

Family: Colchicaceae

Sanskrif Name: Langali, Agnisikha

Kannada Name: Karadi Kannina Gadde, Huliyuguru, Sivasakthi Balli

Threat Status: Vulnerable(a l c,D)- Ka \&KI

Habit: Climber

Habitat: Sea level to semi evergreen forest in a wide range of habitats except desert

Medicinal Uses: The tubrous roots are useful in curing inflammation, ulcers, scrofula, bleeding piles, white discharge; skin diseases, leprosy indigestion helminthiasis, snake bites, baldness, intermittent fever and debility. Roots are given internally as an antidote for snake poison. Considered useful in promoting labour and expulsion of the placenta. If consumed in large doses, it is highly poisonous, it causes vomiting, purging, stomachache and burning sensation. Seeds are used for relieving rheumatic pain and as a muscle relaxant.

Trade Information: local, regional and global

\section{Conservation of Microbial Bio-diversity}

Home garden diverse plantation will not only conserve threatened plant species, it will also attribute to increase diverse microbial bio-diversity that seldom mentioned or no attention in overall reviews of biological diversify. In ecosystems, microorganisms are important as symbionts (endophytes, mycorrhizae, and in insect guts), in nitrogen fixation (Rhizobia, Cyanobacteria, Cyanobacteria-containing Lichens), in the biodegradation of dead animal and plant material, and in controlling the size of populations of plants and insects through natural bio-control. The applications of micro-organisms in the bio-control of pests and weeds are becoming increasingly recognised. In developing countries, major Short- And Medium-Term 
benefits can be expected from improve inocula for mycorrhizae and nitrogen-fixing rhizobium strains; these improve tolerance to environmental stress and reduce the need to apply artificial fertilisers, respectively (mantell, 1989).

\section{Conclusion}

- Realization of our responsibility towards our nature

- Bringing awareness among people.

- Necessity of preventing further loss of rights for patency.

- Conservation and prevention of extinction of species

This Is An Urge To Make A Better Future 